\section{Ukrainian science needs elixir of youth}

Ukraine's science system stands to benefit from its association with the European Union (EU) Horizon 2020 flagship research programme (Nature http:// doi.org/4kq; 2015). But it has problems beyond funding: the re-election of Boris Paton as president of Ukraine's National Academy of Sciences at the age of 96 is symptomatic.

We are involved in an initiative to boost cooperation between the EU and Ukraine in biomedicine (COMBIOM). In our view, this will be difficult as long as young scientists feel that they are being held back by the rigid Soviet-style system run by scientists of the old school. Early-career researchers want to gain experience abroad and have little incentive to return.

Ukraine's science system must be made more competitive. It should reward young scientists who have international expertise and enable them to lead research teams. It should encourage job flexibility and contracts for academy researchers, and identify strategies and research areas to optimize scientific development. It should create institutions that specialize in those areas, and appoint an independent body of EU researchers and Ukrainian scientists abroad to evaluate internal funding applications.

Such measures would create a healthy scientific community and promote Ukraine's integration with the European Research Area. Yegor Vassetzky CNRS-Institut Gustave Roussy, Villejuif, France. Ivan Gout University College London, UK.

Jacek Kuznicki International Institute of Molecular and Cellular Biology, Warsaw, Poland. vassetzky@igr.fr

\section{Improve oversight of fracking in China}

We are concerned that China is paying insufficient attention to earthquakes that are induced by injecting huge volumes of waste water deep underground (see also Nature 520, 418-419; 2015).

Most of China's shale-gas resources lie near seismic fault zones. Wastewater injection by Chinese oil and gas industries has induced minor earthquakes in Sichuan, Chongqing, Xinjiang, Henan, Liaoning and Hubei -6 of 13 provinces prioritized for shale-gas exploitation (see go.nature. com/uriceh; in Chinese). In Chongqing's Rongchang gas field, for example, 32,000 surface earthquakes were recorded between 1998 and 2006 (X. Lei et al. J. Geophys. Res. Solid Earth 113, B10310; 2008).

Replacing coal with gas is central to China's plans to reduce air pollution and carbon dioxide emissions. We call for stricter regulation and tighter monitoring of its fracking industry to curb seismic activity and environmental pollution (see H. Yang et al. Nature 499, 154; 2013).

Hong Yang University of Oslo, Norway.

Julian R. Thompson, Roger

J. Flower University College

London, UK.

hongyanghy@gmail.com

\section{Use '4Rs' criteria to assess papers}

We propose a '4R' approach to assessing reported research, underpinned by statistical rigour (see J. T. Leek and R. D. Peng Nature 520, 612; 2015). These 4Rs denote reproduction, replication, robustness and revelation.

Journals are aware of the need for the first two: whether enough information is available to reproduce an experiment, and whether its original results can be replicated. Even if the experiment can be reproduced, replication is often an issue, so journals are increasingly asking authors for details of software code and raw data. Videos of each experimental step could also be included.

Variations in experimental and analytical methods are a concern for referees and readers, hence the need for robustness. A wellconducted study should indicate the sensitivity of its conclusions to the various assumptions that were made in deriving them.

Revelation relates to the need for accountability and transparency. Scientists must communicate more effectively by disclosing their reasoning for how they develop strategies, derive insights and draw conclusions.

Adrian Pagan University of Sydney; and Melbourne Institute of Applied Economic and Social Research, Australia.

Benno Torgler Queensland University of Technology, Australia. benno.torgler@qut.edu.au

\section{Bird sequencing project takes off}

On 3 June, the Avian Phylogenomics Consortium announced its 'Bird 10K' project to generate draft genome sequences for about 10,500 extant bird species over the next 5 years.

The sequences, along with data we aim to collect on the morphological, physiological, ecological and behavioural traits of every bird species, will inform studies on avian evolution, ecology, population genetics, neurobiology, development and conservation. They could also be useful for investigating infections that pass from animals to humans, such as avian influenza.

This wealth of information will allow us to complete the genomic tree of life for modern birds. We hope to decode the links between genotypes and phenotypes; to determine genetic evolutionary, biogeographical and biodiversity relationships across species; and to evaluate how ecological factors and humans affect bird evolution.

We plan to conduct the project in four phases, based on the avian classification hierarchy. The first, ordinal phase (for 34 orders of birds) has been accomplished (see also G. Zhang et al. Science 346, 1308-1309; 2014). Collection of genomic data for the second, familial phase (about 240 families) is ongoing. Specimen and traitdata collection for the third phase (2,250 genera) and the fourth phase (the remaining 8,000 or so species) is under way. See http://b10k.genomics.cn for more information.

Guojie Zhang ${ }^{\star}$ China National GeneBank, BGI-Shenzhen, China. zhanggj@genomics.cn ${ }^{\star}$ On behalf of 6 correspondents (see go.nature.com $/ v 9$ sl $8 z$ for full list).

\section{Diagnostic service shares BRCA data}

As a partner in the BRCA Share initiative for breast-cancer genetic data, we wish to clarify our position (see Nature 520, 585; 2015).

Quest Diagnostics tests one in three US adults annually, including for BRCA gene mutations. We support openaccess sharing of these data, once the complexities of uploading so many records can be resolved.

A final test run for uploading Quest data to the Leiden Open Variation Database (LOVD) is now complete. Contrary to your implication, we anticipate that the publicly available database funded by the US National Institutes of Health, ClinVar, will eventually have access to these data because of a reciprocal relationship with the LOVD.

Industry is often criticized for not giving back. Labs that make revenue from $B R C A$ testing pay to participate in BRCA Share; academic scientists and entities do so for free. This reduces the need for public funding to improve BRCA tests. Some of the fees will go to functional studies of BRCA variants. BRCA Share also raises the bar of responsibility for commercial labs.

Charles Strom Quest Diagnostics, California, USA.

charles.m.strom@

questdiagnostics.com 